\title{
A Preliminary Study of Euphemism from the Perspective of Ecolinguistics
}

\author{
Huaxue Wang ${ }^{1, a}$ \\ ${ }^{1}$ Northeast Petroleum University, Daqing, Heilongjiang 163318 \\ ${ }^{a}$ Email:whx999@sina.com

\begin{abstract}
Euphemism, as a linguistic phenomenon, provides a suitable and comfortable way of expression for human communication. It is a reflection of the development of human civilization as well as a carrier of human cultural development. As a new subject, ecolinguistics provides a new perspective for the analysis of euphemisms. Through the analysis of the ecological influences on the origin, development process and language characteristics of euphemism, it is found that the development law of euphemism is consistent with the law of ecological evolution, which can deepen the understanding of the laws of language evolution and language diversity, and is of great significance for guiding the use of euphemisms and an effective inter-cultural communication.
\end{abstract}

Keywords: Euphemism, Ecolinguistics, Linguistic diversity, Language evolution

\section{INTRODUCTION}

Euphemism is a phenomenon coexisting in the languages of various nationalities in the world. It is an important means of expression in our modern interpersonal communication. We use tactful and gentle methods, such as metaphors, borrowings, detours, abbreviated harmonious rhyme, to fully express our various thoughts, and cleverly avoid embarrassing, unpleasant, disgusting and frightening situations on both sides. A large number of euphemisms arise from this, and are widely used thereafter. As the American scholar pointed out, no one-including those who pretend to be most straightforward - can one day not use euphemisms. Considering the interviewer's occasion, the close relationship between the interviewer and the communication partner, euphemisms reflect a kind of social culture, various cultural differences, social and cultural phenomena, and people's psychology. Therefore, euphemisms are widely regarded as good lubricant in interpersonal communication, which plays a vital role and carries a long history and culture.

Language is not only the social language of human beings, but also an ecological language. It has been 40 years since the birth of ecolinguistics. It reflects the complex relationship between human society and the ecological environment, in which euphemism is a micro-context, and appears in a certain social environment and varies according to the social environment. Analyzing the ecological laws of euphemisms from the perspective of ecolinguistics, it is found that euphemisms and their language environment as well as biological environment have similar laws of evolution and diversity, which will help us use euphemisms correctly and understand the corresponding cultural background.

\section{LITERATURE REVIEW}

\subsection{Ecolinguistics}

The concept of "ecology of language" was first proposed by Einar Haugen of Harvard University in 1972[1]. Haugen first proposed the "metaphor" of language ecology, comparing the relationship between language and language environment to the ecological relationship between living things and living environments, and comparing language environment to biological ecological environment. Especially the influence of social ecological environment on language. According to Haugen, language ecology studies "the interaction between a specific language and the language environment." Many scholars have recognized the "metaphor" of Haugen's language ecology, calling it the "Haugen model", which laid the foundation for language ecology. This model mainly focuses on issues such as language diversity, language contact, language demise, language planning and so on. 
Halliday gave an insightful speech on the non-ecological factors of the language system at the International Conference on Applied Linguistics, which focused on the role of language in ecological and environmental issues, thereby promoting the study of language and ecological issues[2]. Ecolinguistics is a cross-discipline formed by the integration of ecology and linguistics. It is an emerging branch of linguistics that has developed in recent decades[3]. The Halliday model emphasizes the influence of language on the environment, especially on the natural environment. The main concern is the impact and role of language in environmental degradation and its contribution to environmental protection. Therefore, the "Halliday model" is often referred to as "environmental linguistics".

The research of ecolinguistics in China started relatively late. According to the literature, the earliest research on language ecology in China was from Zheng Tongtao and Li Guozheng, which were mainly embodied in the ecological study of Chinese. Li Guozheng divided language into an external ecological environment system and an internal ecological environment system. The former is composed of three parts: natural environment, social environment, cultural environment; The systems are interconnected and influenced each other, which together constitutes the inner ecological environment of the language, and promotes the development and change of the language system. Feng Guangyi published the first book entitled "Ecolinguistics"[4]. In addition, some scholars discuss translation issues from an ecological perspective. At present, domestic ecolinguistics research generally include the following three aspects: ecolinguistic research from the perspective of ecological discourse analysis; research on Chinese endangered languages from the perspective of ecolinguistics; research on the integrity and diversity of language systems from the perspective of ecolinguistics .

The current research content and methods of ecolinguistics involve linguistics, psychology, ecology, geography, history, etc., reflecting the interdisciplinary research of ecolinguistics.

\subsection{Language Evolution}

In the mid-nineteenth century, German historical linguist pointed out that language developed its own way, just like the evolution of organisms. Scholars during the period associated language with living things and believe that language, like living things, has also experienced the life process of birth, growth, aging, and death.

Since the publication of Darwin's "Origin of Species", linguists have been trying to use evolutionary methods to study language. Linguists hope to find ways to produce, develop and change languages. The further study of language evolution has made significant progress from the biological mechanism of language. Darwin systematically described species evolution as "natural selection" and "survival of the fittest". As the living environment changes, if the development or mutation of species can adapt to this change, they can survive the struggle for survival. If the development or variation of a species cannot adapt to changes in the environment, it will disappear in the struggle for survival.

The development process of euphemisms conforms to Darwin's biological evolution law. Many euphemisms will be born under the social background of different periods. Some euphemisms that do not conform to social development and people's current values will be eliminated, and the remaining euphemisms themselves have the characteristics of survival of the fittest. They varied according to changes in the social environment to meet the requirement of language users in different times.

\subsection{Language Diversity}

The diversity of languages is the most typical feature of the language ecosystem. The diversity of languages refers to the diversity of the internal elements of the language and the diversity of the language environment. Language diversity is closely related to biological diversity, and is a direct manifestation of cultural diversity. There are many factors that affect language diversity, such as geographical environment, historical conditions, and human factors. There is a certain relationship between linguistic diversity and biodiversity. Researchers from the University of Oxford in the United Kingdom, Pennsylvania State University in the United States, and Conservation International found that the biodiversity-rich areas of the world also contain more linguistic and cultural diversity. Studies have shown that $70 \%$ of the world's known languages (4,824 languages) are distributed on less than a quarter of the earth's continents. Less than 10,000 people in the world speak more than 4,000 languages, and 2,804 languages have been found in biodiversity hotspots. The reduction of the number of species on our planet is mostly due to the decline in linguistic diversity. Linguistic diversity is one of the three core concepts of ecolinguistics, and it is also the most prominent feature of the language ecosystem. Experts and scholars in China and foreign nations have also made great contributions to the protection and development of ecolinguistics. Therefore, to protect linguistic diversity is to protect biodiversity. It is especially vital to protect language diversity. 


\section{THE IMPACT OF ECOLOGICAL ENVIRONMENT ON EUPHEMISM}

\subsection{Influence On The Origin And Development Of Euphemism}

Euphemisms are similar to the laws of biological evolution and have the characteristics of natural selection. As a new species, euphemisms appear and are related to nature and religious superstitions. People feared nature in ancient times. In order to get shelter, they worshiped gods and other magic things, and never directly called their names, so they came up with euphemisms to express worship and devotion for God.

As time goes by, mankind has entered a period of civilized social development. Social development and changes will inevitably be reflected in language. The language in the concept of ecolinguistics and natural environment in which the language is located are also mutually restrictive and mutually influenced. However, the developing society was accompanied by social factors such as fluctuating social economy and the ravages of war, which lead to people's dissatisfaction with the social environment. Offensive and insulting words greatly polluted the language environment; drastic changes in the environment for the survival and development of language provided soil and nutrients for the vulgarization of language, and vulgar language and curse had a breeding ground. In order to maintain social harmony and stability, the government vigorously advocated the use of civilized euphemisms to innovate negative language phenomena, suppress the rioting social order, and improve the vulgar and ignorant social environment. As a result, euphemisms about nature and feudal superstition, unable to adapt to the changes in the social environment, gradually declined and went to extinction. During this period, euphemisms developed along with the use of taboos. In order to reduce the influence and destructive power of vulgar language, euphemisms came into being, thus maintaining the balance of the language ecological environment. Today, with advanced technology, a large number of euphemism proper nouns about the new era will emerge endlessly. At the same time, with the emergence of the Internet, Internet euphemisms need to survive through external and internal competition.

At present, outspokenness had a slight upper hand in contemporary language expression styles, but as people's moral standards continued to be improved, their requirements for respect for human nature will become stronger, so language civilization is still indispensable, and euphemisms are also available. The reason for continuing to exist in many fields can continue to serve as an indispensable "lubricant" in interpersonal communication. However, if euphemisms are to maintain the balance of the language ecological environment, it must continuously expand its influence in language communication in order to maximize its potential in the great historical process of establishing a harmonious society as well as a harmonious world.

\subsection{The Impact Of The Ecological Environment On The Diversity Of Euphemisms}

\subsubsection{On The Diversity Of Euphemism Language Characteristics}

\subsubsection{On Pronunciation}

When we encounter some words that we dare not say but have to say, sound-saving, phonetic distortion,the rhyming substitution, homophony and interruption can be employed in the discourse. For example:

1) Sound-saving: such as using "vamp" instead of "vampire";

2) Phonetic distortion:The phonetic distortion intentionally changes the pronunciation of taboo words to avoid taboos, such as: gosh (God)

3) The rhyming substitution method: rhyming slang uses the rhyming characteristics of some words and taboo words to replace them, such as: sis, (piss)

4) Homophony: Homophony is to use the condition of homonyms or near sound in Chinese characters, and replace the original character with homophone or near sound. For example: in Chinese, Tongchang will use homonyms to avoid taboos.

5) Interruption in the discourse: In daily conversation, people are often excited to say something inappropriate. At the same time, they want to stop the conversation in time, so they use words like "oh, ah, come on, okay" to change the euphemism, or temporarily move to the next topic.

\subsubsection{On Word Formation}

The diversity of euphemism is also reflected in the way of word formation. A large number of word formation methods provide rich resources for euphemism neologisms, and also provide a sufficient corpus for our human communication.

1) Abbreviation:It refers to combine the first letters of awkward words or sensitive words in daily life to replace direct taboo words, such as: DA (drug addict); WC (water closet) toilet.

2) Compounding. It refers to the combination of two or more words into one euphemism, such as: restroom (rest + room, namely toilet), sleepyhead (sleepy + head, namely lazy man).

3) Clipping. Truncation is to decapitate some words to cover up, such as gents (Gentlemen's Room, men's toilet), ladies (Ladies's Room, ladies' toilet), etc. 


\subsubsection{On Syntactic Level}

1) Using subjunctive mood.

This can make the tone more polite and appropriate. For example, "If I were you, I would not refuse his request."

\section{2) Using past tense.}

The past tense can be used to express euphemistic requests, tentatively point out the mistakes of others, or give a suggestion. For example, "I was hoping that I would see my dear friend next month." It's more euphemistic to use the past continuous tense than the present tense.

\section{3) Using tag questions}

In this way, you can have a strong sense of negotiation to avoid being too direct and affirmative, and achieve the purpose of politeness and euphemism. For example, "If you do this, she will be sad, right?"

\subsubsection{On The Diversity Of Euphemism Applications}

Euphemisms play an indispensable role in the language ecosystem. In communicative conversation, each field will have its specific euphemism expression, showing the characteristics of diversity. The diversity of euphemisms in application fields is reflected in life and society. In daily life, when conversations involve privacy-sensitive topics or in order to avoid unpleasant occurrences, people often choose to use euphemisms to avoid being presumptuous or rude. Euphemisms can also be applied in the following fields:

\section{1) Professional field}

Professional euphemisms can meet people's psychological needs to avoid the confusion of professional groups, and promote social harmony and interpersonal communication. Generally, we divide work into blue-collar and white-collar jobs. White-collar workers are considered to be noble work, while blue-collar workers are considered to be humble and dirty. For example, "cleaners" are called "sanitary engineers"; "gardeners" are called "landscape technicians".

\section{2) Commercial field}

In order to promote the sale of goods and persuade consumers to buy goods or accept certain services, businessmen try to use words with pleasant associations instead of unpleasant words or expressions. Businessmen will use a large number of adjectives full of positive meanings and bring good associations to people. For example, queen size replaces oversize clothes.

\section{3) Educational filed}

With the development of the times, euphemisms appear in large numbers in education. For example, "relying on others to do his/her work" actually means "cheating in the classroom" For a student who likes to lie, we say that he has a tendency to exaggerate the truth. It can be seen that the use of these euphemisms not only helps teachers educate students, but also helps maintain students' self-esteem, thereby reducing the distance between teachers and students and creating a harmonious classroom atmosphere.

\section{CONCLUSION}

Ecolinguistics explores the relationship between language and environment, studies the ecological characteristics of human language, analyzes and applies the ecological principles of language, and reveals the ecological laws of language development. Under certain historical conditions, language will inevitably change with the development of history. The emergence and evolution of language is inseparable from the natural and social environment at that time. The expressions of euphemisms in different fields and various means of word formations show the characteristics of biodiversity. It is also a prerequisite for maintaining the balanced development of the language ecosystem. The diversity of euphemisms provides continuous nourishment for the existence and development of the language system, and also lays the material foundation for language communication in our lives. It has an inestimable effect on our understanding of history and contemporary society.

\section{ACKNOWLEDGMENTS}

This research was financially supported by Creative Foundation of Northeast Petroleum University-A Study on the Present Situation of Heilongjiang Dialect from the Perspective of Eco-linguistics. (Grant NO. 2020YTW-W-06)

\section{REFERENCES}

[1]Einar Haugen, "The Ecology of Language", Alwin Fill and Peter Mühlhäusler eds., The Ecolinguistics Reader: Language, Ecology and Environment, London and New York: Continuum, 2001, p. 57, 59.

[2]Halliday, M.A.K. New ways of meaning: The Challenge to applied Linguistics. Journal of Applied Linguistics, 1990, pp,7-16, Reprinted in Webster. J. (ed.).

[3]Huang, Guowen \& Chen Yang. A review of Alwin Fill's studies of ecolinguistics. Journal of Poyang Lake, 2016, pp, 19-24.

[4]Feng, Guangyi. An Introduction to the Ecology of Language. Beijing: Renmin Press, 2013. 